\section{My greatest experiment}

\author{
Ronit Satchi-Fainaro reflects on decision making in science and in life.
}

$\sigma^{\circ}$ cience is hypothesis-driven. It is based on the collection of data obtained by cutting-edge methodology. After formulation, a hypothesis is empirically challenged by comparing it to distinct control groups, and then discussed in relation to all the theories, facts and figures that others have obtained. Finally, at the temporary completion of this process, the data and conclusions are assembled into a manuscript, often torn apart by reviewers. I can attest that in cancer nanomedicine all of this is well worth the potential reward of having the work translated to the clinic and making a difference.

As a scientist, I'd like to say that I base not only my work but also my career and personal decisions on this schematic cascade, but in all honesty, that's not always the case. Some of the most important, life-changing decisions I've taken were made almost instantly, guided mostly by instinct and intuition.

My faith in and love for the scientific process notwithstanding, I think that in life we sometimes overthink big decisions. My wonderful $\mathrm{PhD}$ advisor, Helmut Ringsdorf, once told me that life and science are way too serious to be taken seriously. It sounded like good advice, and it turned out to be absolutely right in regard to the way my life and academic career evolved. Lightweight decisionmaking is how I ended up doing cancer nanotechnology.

1995 was a tough year. My personal self lost a great friend, when an unfortunate encounter between a flock of storks and the F-15 that he was piloting ended tragically. My collective national self lost a great leader, when, three months later, Prime Minister Yitzhak Rabin was assassinated. Following these two tragedies, my best friend - the pilot's widow - and I decided to take a break for a week in London, thinking that some cold fresh air combined with quality comedy theatre would be useful in launching a long healing process. Two hours before one of these West End shows, I met Ruth Duncan at The University of London, following the advice of a friend who thought that the field of research that Duncan was investigating in her lab would be a perfect fit for me. Duncan introduced me to the fascinating field of polymer therapeutics and their application in cancer nanotechnology.
It very much hit a nerve, as six years earlier I saw my father dealing with the horrendous side effects of chemotherapy. I was immediately smitten. It took me two minutes to decide that I wanted to do my $\mathrm{PhD}$ there - much less time than it had taken my friend and I to pick the show to see that night. We ended up seeing five plays that week, all of them opening with a funeral scene! So much for comic relief and for the careful decisionmaking used to plan our much-needed escapism. But the one rapid decision I made that week turned out to be brilliant - and changed my life.

\section{Be brave in your choices, embrace challenge and} chance breaks.

A few years later, the decision to go to Boston Children's Hospital and Harvard Medical School for a postdoc with the great, late Judah Folkman took no longer than the first one. Following a brief encounter at a conference, I ended up walking Folkman to his hotel to take a cab back to the airport. Folkman offered me a postdoc in his lab. He told me that the last person doing polymer chemistry in his lab was Bob Langer about 30 years earlier. I needed nothing more to convince me. I always believed that trying to fill large shoes is way more comfortable and spacious than squeezing into tight ones. Only in retrospect did I realize that Folkman never stayed after giving a plenary lecture. I was just lucky that he was polite enough to stay in the hall and hear my talk before the coffee break.

Over the next six months Folkman sent me the Boston Globe Magazine every week, marking available positions at law firms for my husband, who would also need employment should we relocate to Boston. I knew then that this was the right decision. Combining nanotechnology with cancer and vascular biology was a bonus, working with Folkman was the true privilege. Leading by example, he taught me to follow my curiosity, never to ignore serendipity, to be persistent on how I run my research but especially to think big and ask paramount questions, disregarding minor details such as budget or the possibility of experiments going wrong. He called this "the so-what assay". Imagine that you got all the grants you applied for, and that all the experiments worked exactly the way you predicted ... So what?! How would it change our perception of the current knowledge? Every time a project is close to fruition, we look once again at the details and find more flaws. Though the puzzle is never completed and there will always be plenty of small imperfections, often these cracks are how the light gets in, as Leonard Cohen so beautifully and precisely wrote.

Since then, these small compromises are part of my life as the principal investigator of my multidisciplinary research lab. Immediately after a postdoc, we are expected to be CEOs, architects and economists, with no proper preparation. We should know how to design a lab, and which decision to make regarding everything, from workspaces and IT to electricity and plumbing. We need to be politicians and psychologists, advising our students on their greatest choices in life, managing multiple budgets and coping with a lot of ego from some of our colleagues.

As I explored these unknown territories over the years, I tried to keep Helmut Ringsdorf's advice in mind: that life and science are too serious to be taken seriously. This does not mean that I skip through life and science carefree - I often debate, research, consider and reconsider. But for me, when opportunity knocked, being courageous by making quick decisions proved a worthy choice. You never know if such opportunities will come again, so don't waste too much energy on trivialities. You can back off later if it doesn't work out. Be brave in your choices, embrace challenge and chance breaks, delegate to people you trust. Just like in science, so much of life is unknowable in advance - you have to run the experiment to get the answers.

\section{Ronit Satchi-Fainaro ${ }^{1,2}$ \\ ${ }^{1}$ Head of the Cancer Angiogenesis and Nanomedicine Laboratory, Chair of the Department of Physiology and Pharmacology, Sackler Faculty of Medicine, Tel Aviv University, Tel Aviv, Israel. ${ }^{2}$ Chair of the Herman and Kurt Lion Cathedra in Nanosciences and Nanotechnologies, Tel Aviv Univeresity, Tel Aviv, Israel. e-mail:ronitsf@tauex.tau.ac.il}

